

\title{
Amplifying the learning effect via a Forecasting and Foresight Support System
}

\author{
Georgios P. Spithourakis ${ }^{\mathrm{a}}$, Fotios Petropoulos ${ }^{\mathrm{b}, *}$, Konstantinos Nikolopoulos $^{\mathrm{c}}$, Vassilios \\ Assimakopoulos $^{\text {a }}$ \\ ${ }^{a}$ Forecasting and Strategy Unit, School of Electrical 8 Computer Engineering, \\ National Technical University of Athens, Greece \\ ${ }^{b}$ Lancaster Centre for Forecasting, Department of Management Science, \\ Lancaster University Management School, Lancaster University, UK \\ ${ }^{c}$ Bangor Business School, Bangor University, UK
}

\begin{abstract}
Nowadays, informed decision making is conducted through innovative Information and Communication Technology (ICT) support systems. In order to fully utilize such ICT-based support systems, suitable training of decision makers needs to be performed. This paper proposes and evaluates the use of a Forecasting and Foresight Support System in an undergraduate course in Business Forecasting so as to amplify the learning effect. The system provides a simple implementation of the forecasting process via realistic business scenarios that utilize both quantitative and qualitative information. Classical operational forecasting related features as well as elements of a foresight nature are considered during an exercise, so as to enhance user experience in terms of collaboration and communication. System acceptance and perceived educational effects are validated through responses to a purpose-built questionnaire. The results are very encouraging in terms of the final amplification of the learning effect.
\end{abstract}

Keywords: decision support system, training system, judgmental forecasts, hierarchies, reconciliation, forecasting course

\section{Introduction}

The term Forecasting Support System refers to sets of procedures that facilitate interactive forecasting of key variables in a given organizational context (Ord and Fildes, 2013). These include all aspects of operational forecasting, such as data preprocessing, statistical modeling and monitoring processes, while offering the ability to the users to perform judgmental interventions to the statistical estimates (Goodwin et al., 2007). Forecasting support systems can be viewed as integral parts of decision support systems (Fildes and Goodwin, 2013).

Foresight extends forecasting in the sense that it incorporates aspects of networking and preparation of decisions related to the future (Cuhls, 2003). Therefore, Foresight Support Systems may

\footnotetext{
${ }^{*}$ Correspondance: F Petropoulos, Department of Management Science, Lancaster University Management School, Lancaster, Lancashire, LA1 4YX, UK.

Email address: f.petropouloselancaster.ac.uk (Fotios Petropoulos)
} 
be defined as "collaborative computer-based systems aimed at supporting: communication; decision modeling; rules of order in foresight processes" (Banuls and Salmeron, 2011). Such systems should combine knowledge base and group models with quantitative data processes (Skulimowski, 2012).

Forecasting support systems, as defined above, may be used by more than a single user, especially in the case of hierarchical data structures. In this case, it is common for different users (managers) who need to perform forecasting tasks at different levels of hierarchy (cross-sectional aggregation). This results in several sets of forecasts across the pyramid structure of a companys data, rendering the reconciliation of such forecasts quite challenging. A natural solution in order to tackle this problem would be an extension of an innovative forecasting support system so as to include standard features of foresight support systems. This could be achieved in many ways, but predominantly in terms of web-based ready mechanisms that enable the (a)synchronous interaction between users of different managerial levels. Instead of using statistical procedures to deal with the reconciliation of forecasts (Athanasopoulos et al., 2009), the users can decide on the reconciliation process themselves and act as necessary. This strategy is expected to result in consensus among forecasts derived from different users, rendering managers at different levels of hierarchy dependent on each others opinions. Moreover, collaboration and networking features allow users to analyze and share their views and opinions about the available soft data, on which any judgmental adjustments will be based. In order to facilitate this, a web-based interface seems prerequisite, enabling timely remote connections to this system.

The optimal use of such information systems depends heavily on the users education and training background. This is even more important if we consider that such specialized support systems are crucial for industries relying heavily on them for operations and planning. As such, the appropriate training of the practitioners and business managers is of critical importance. Such training should include a balanced mix of a good understanding of the underlying processes, algorithms and statistical methods of these systems, as well as how information coming from different sources should be managed and used through sharing and collaboration in order to maximize the performance of the forecasting process.

Meeting with modern trends poses a challenge to educational institutes, which have to question the fundamentals of the educational process. Outdated elements must be revised, allowing the integration of new technologies and methods. Institutes have already begun conforming to change by incorporating novel methods of teaching to courses syllabi and making use of computers, when possible. In particular, expert systems have reasonable prospects for diffusion and proliferation (Armstrong and Yokum, 2001). However, they are not yet actively represented in traditional lectures of Business Forecasting and Management courses. Moreover, it is suggested (Haak et al., 2011) that frequent and structured practice via "active-learning exercises" is likely to improve students performance. We suggest that a combination of lectures and tutorials on statistical forecasting methods and processes together with an advanced support system that simulates the business forecasting and foresight cycle will result to the amplification of the learning effects and outcomes, with students gaining a holistic statistical and business perspective understanding.

The current paper builds on the insights presented in the previous paragraphs and proposes an innovative support system that combines features from both worlds into a Forecasting \& Foresight Support System ( $\left.\mathrm{F}^{2} \mathrm{SS}\right)$. Building on the idea of a standard forecasting support system, features from the world of foresight support systems come into play. A schematic view of our approach is presented in Figure 1. 


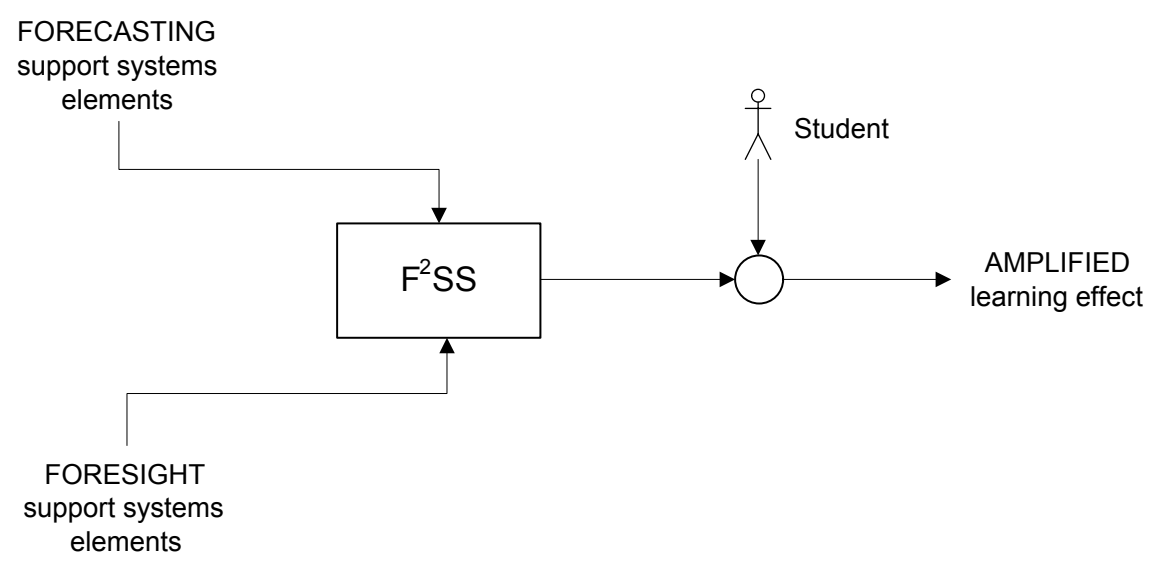

Figure 1: Forecasting \& Foresight Support System for amplifying the learning effect of students.

A direct objective of this study is to measure the systems effect on the learning process when used as a training tool in a Business Forecasting course. In order to achieve this, a prototype system of the proposed framework is introduced to a team of student-users and the perceived impact on their learning experience is measured and analyzed. The custom-built exercise includes traditional aspects of a forecasting support system and simulates a realistic business scenario. Moreover, while features of foresight systems are gradually included, the satisfaction in the collaboration among users in the same group and the influence among different hierarchical levels towards the reconciliation of final estimates are examined. The objective of this paper is to measure the effectiveness of such a system towards the better understanding of forecasting and foresight, the acceptance of the system and its perceived impact. The paper explores the effectiveness of forecasting and foresight support systems and measures the positive gains by including a specialized system in the curriculum of a Business Forecasting course.

The remaining of the paper is structured as follows: Section 2 presents a literature review of features generally integrated in Forecasting Support Systems and gives an insight on how to expand with foresight aspects. Moreover, a short review of the use computers in education is provided. Section 3 discusses the realistic business simulation that we will explore in the current research, while Section 4 presents the $\mathrm{F}^{2} \mathrm{SS}$ prototype based on the required features. The analysis based on the users feedback is presented in Section 5, while Section 6 gives conclusions and draws paths for future research.

\section{Literature review}

\subsection{Forecasting process and forecasting support systems}

The fundamental objective of forecasting is the estimation of the yet unobserved values of a time series, which is a collection of data points measured at successive times and typically spaced at uniform intervals. While there is no universally "correct" implementation of the forecasting process, as this depends on the data, the objectives and the forecast horizon, a typical forecasting process includes analysis, pre-processing and visualization of the data, statistical estimation of the future values, judgmental adjustments upon the statistical estimates and monitoring of the forecasts as new values become available. The current subsection will deliver a short background on the sub-processes of each step of this process. 
Given that a time series represents the actual values (e.g. sales) sampled in a predefined frequency (e.g. 12 periods per year for monthly data, or 4 periods per year for quarterly data), the first step of the pre-processing phase for fast-moving time series would be to split the data into four distinct elements: trend, cycle, seasonality and randomness. Ideally, one can identify the different components of a time series through a process of decomposition. Classical decomposition method (Makridakis et al., 1998) is often used to decompose the time series into its different sub-patterns. In a simple scheme applied in major empirical studies (Makridakis and Hibon, 2000), trend, cycle and randomness are left intact and partly dealt with later on, while seasonality is extracted from the original data resulting into the deseasonalized data time series. The information of seasonality is stored for later use in seasonal indices, as many as the periods per year of the time series.

Graphic plots can help identify the significant patterns and unusual values (Hyndman and Athanasopoulos, 2013), providing useful insights (Ord and Fildes, 2013). On the other hand, numerical data summaries (statistics) of the original data can provide us with a number of helpful quantitative attributes in the form of simple or more complex statistical measures (Makridakis et al., 1998). This analysis usually includes statistical measures such as the minima and maxima of the series, its mean value, standard and mean absolute deviation and the coefficient of variation.

A statistical forecasting method is a statistical treatment applied to a time series, so as to extrapolate data into the future, according to their behavior and tendencies in the past. The application of various simple extrapolation methods has been proved robust in large empirical set ups (Makridakis et al., 1982; Makridakis and Hibon, 2000). Methods that are usually integrated in statistical software include Nave, Moving Averages and simple methods of the Exponential Smoothing family, such as Simple Exponential Smoothing (Brown, 1956), Holt (Holt, 1957) and Damped (Gardner and McKenzie, 1985). In recent years, Theta method (Assimakopoulos and Nikolopoulos, 2000) has been integrated in many forecasting packages (Tavanidou et al., 2003; Hyndman and Khandakar, 2008; Makridakis et al., 2008), given its very good performance in previous studies (Makridakis and Hibon, 2000).

Based on the statistical analysis and preprocessing of the data, an appropriate method is selected and applied to the deseasonalized data. Finally, statistical estimates are reseasonalized. A list of measures indicating the goodness of fit (e.g. mean squared error, coefficient of determination R-square) and forecasting accuracy (e.g. mean absolute error) allow the decision makers to verify the appropriateness of the alternative methods. Poor fitting or inadequate forecasting performance may be indicators towards the revision of the choice of a suitable forecasting method.

External information, e.g. rumors or announcements about the future of the measured variable, is sometimes available to the decision maker. Such information is often called soft data, as opposed to hard data, the factual data used in the statistical analysis. In practice, forecasters often combine soft data with their own intuition and expertise to make a judgmental adjustment on the statistical estimate (Fildes and Goodwin, 2007), but measures should be taken so that this integration does not have an adverse effect (Fildes et al., 2009). Usually, the forecaster derives the final forecast as a weighted average of the statistical and judgmental forecasts. A simple combination is often regarded as an efficient strategy (Armstrong and Collopy, 1998), resulting in improved forecast accuracy (Song et al., 2013).

Hierarchical structures of data are very common in industrial and commercial applications, as total sales can usually be disaggregated into different divisions and various products. The most common approaches for calculating forecasts at every hierarchical level are the top-down and bottom-up approaches. The bottom-up approach (for example see: Dangerfield and Morris, 1992) 
refers to the appropriate summation of the forecasts of the lowest level in order to calculate forecasts at every higher level. In the top-down approach, forecasts are calculated only at the top level and then are disaggregated using historical (Gross and Sohl, 1990) or forecasted (Athanasopoulos et al., 2009) proportions. While both approaches work towards the reconciliation of forecasts at every level, the estimation of the base forecasts at either the lowest or the highest level of aggregation results in problems related to noise or loss of information, respectively. If forecasts are to be calculated at every level of the hierarchy, optimal combinations (Athanasopoulos et al., 2009; Hyndman et al., 2011) or more qualitative approaches should be considered.

A common strategy across companies is to regularly update their forecasts every period (or every few periods) in order to incorporate new data points as these become available. Such a strategy can be assisted through monitoring processes. In particular, corrective actions should promptly be taken when systematic forecast errors are detected. These can be caused either by poor forecasting methodology or by a pattern change or level shift of the data. Triggs series monitoring method (Trigg, 1964) is regarded as one of the standard methods for this purpose.

A simple and general purpose implementation of the forecasting process analyzed in this subsection is depicted in the flowchart of Figure 2.

\subsection{Foresight}

Foresight does not only consist of a quantifiable estimate of the future state, but also includes the preparation of the strategic actions to be made towards the desired future situation (Cuhls, 2003). Cuhls mentions that this requires more than one participant in the process, describing foresight as "needs-oriented". As different stakeholders are considered, communication and collaboration come into play (Martin and Johnston, 1999), in an attempt to deal with uncertainty (Van der Meulen et al., 2003). To achieve this interaction between different participants, aspects of knowledge management must be integrated into the decision support process and the respective information system (Skulimowski, 2012). Companies typically make use of soft data, such as rumors and published news items.

We suggest forecasting support systems should be extended to include aspects of foresight support systems. This will be made possible by utilizing networking and collaboration between the users of a forecasting support system, which would allow soft data to be analyzed in a collective manner. Interaction group approaches also allow for better estimation of the impact of special events (Nikolopoulos et al., in press). Moreover, judgmental reconciliation of the discrepancies in the estimates derived from different hierarchical levels can now resolved on common ground. Students studying forecasting should be introduced to concepts such as strategic foresight and long term technological forecasting. Finally, collaboration, communication and interaction between the members of a forecasting team will enhance the decision making experience, bridging the gap between forecasting and foresight.

\subsection{Computers and education}

Computers have been used in education since the dawn of computer age. Examples of educational software include support systems (Parikh and Verma, 2002), such as Group Support Systems which have been used to study individual and group behavior and facilitate remote team work and collaborative learning (Ready et al., 2004; Sawyer et al., 2001); computer simulations of processes that are either too costly or time consuming to otherwise carry out (McKone and Bozewicz, 2003; Shannon et al., 2010); learning environments (Fortune, 2007; Stricker et al., 2011); and web-based training systems (Helic et al., 2000). Web-based and personalized systems facilitate 


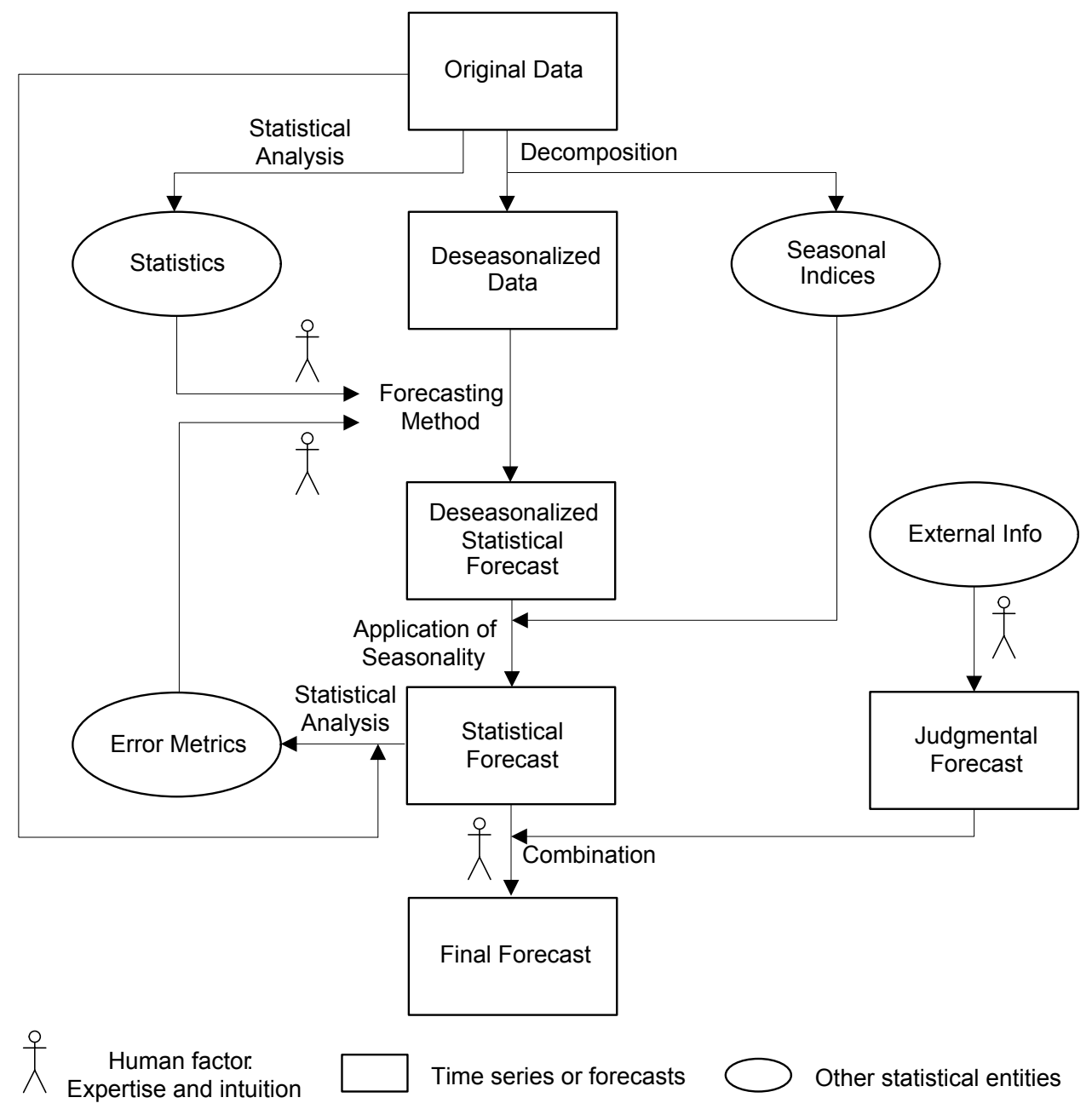

Figure 2: Implementation of the forecasting process. 
concepts as remote connectivity, distance learning and personalized learning. Careful consideration is needed when designing or selecting such software, so as to take full advantage of available resources (Hunter, 1989). In the vast majority of cases, use of computers in education has received positive comments by students (Kulik, 1994). On a review report, Sivin-Kachala and Bialo (2000) state that technology rich environments help students to achieve more positive effects and improve learning and self-concept.

Before students of Business Forecasting and Management courses apply their skills in real life scenarios, they should experiment with the various techniques of forecasting, be safely exposed to the uncertainty of predictions, evaluate their results and learn from their mistakes. There are many applications with forecasting capabilities, ranging from massive, application-specific management information systems to simpler, generic forecasting support systems (Forecast Pro, AutoBox, ForecastX etc.), while e-forecasting services and tools, such as eTIFIS (Tavanidou et al., 2003) or Fourcasting, are constantly arising. Even though such commercial applications are already being used for educational purposes, to the best of our knowledge no dedicated web-based trainingoriented forecasting system exists. A web-based system would allow the integration of features deriving from the worlds of forecasting and foresight support systems. Analysis of the direct educational outcomes deriving from the use of such a system will allow us to better evaluate its significance.

\section{A simulation exercise on Business Forecasting}

A Business Forecasting course (as taught in the eighth semester of the School of Electrical and Computer Engineering of the National Technological University of Athens, aimed at students with a specialization in Management and Decision Making) contains material about time series, their qualitative/quantitative characteristics, statistical or non-statistical forecasting methodology, forecast evaluation approaches and applications of Business Forecasting. Students are also introduced to important aspects of foresight, such as communication of opinions about the future, interpretation of information, distributed intelligence and consensus. The course ultimately provides students with the ability to apply forecasting methods and analyze data needed for planning and decision making.

As a means of accomplishing the above educational aims, students could participate in an elective exercise, as an alternative to being given an extra problem in addition to the courses final exam. This exercise was a simulation game that introduced increasingly realistic business forecasting tools and scenarios, through which students could match theory with practice. Questionnaires were used to measure the impact of this exercise on the perceived learning effect and satisfaction.

After announcement of the exercise and a two weeks registration period, the 83 students that eventually registered in the exercise were randomly split into groups of four (a member of the teaching staff filled in the empty slot in one group). Each group stood for a single company, with students within the groups being assigned at random between two hierarchical levels: a leader that acted as a company manager and their three subordinates that acted as department managers. Each person was assigned three time series (product sales), with all time series within a group forming a hierarchy typical to that found in real-life companies, in the sense that the time series of each subordinate summed into a single time series of the group leader.

The simulation could be stripped down into rounds of analyzing the data, producing point forecasts for each of the three time series and evaluating their forecasting accuracy once the real value became available, therefore forming a rolling forecasting scheme with unitary forecast horizon. 
Six such rounds were carried out, each spanning one week. Students were given much freedom in the way they would choose to produce their forecasts and were encouraged to experiment with different tools and configurations. However, general guidelines that followed the pace of the content taught at the lectures were given. Every week a new concept was introduced that had to be applied in all subsequent weeks as well, so that tasks gradually became more complicated and provided a more realistic business forecasting experience. Foresight concepts that required communication were introduced early on, to allow for more time for interaction among students in the coming weeks.

In the first week, students were asked to produce statistical forecasts using the forecasting method from a specific set of methods that minimized the mean absolute percentage error (MAPE) and then use their intuition to make judgmental adjustments. For the second week, they were given a front page of a financial/technological newspaper. The cover displayed several made up articles and advertisements that would possibly carry an impact on some companys product sales in this period, which they should take into account to perform judgmental adjustments to their forecasts. They were encouraged to communicate with other members of the team to discuss possible implications of this soft information. The task for the third week again called for selection of a statistical forecasting method based on minimization of alternative forecasting error measures and introduced the concept of top-down and bottom-up forecasting to exploit the hierarchical nature of the data. Students were instructed to engage in one round of the top-down (for subordinates) or bottom-up (for leaders) methodology and accordingly revise their forecasts in cooperation with other members. After submitting this weeks estimates, they had to answer a questionnaire (early responses), marking the midpoint of the simulation.

Next, in the fourth week, students had to pick an appropriate exponential smoothing method (constant level, linear trend or damped trend) according to the series qualitative characteristics. In the fifth week, they were asked to use an intermediate, adjusted deseasonalized series to account for the impact of special events in previous periods. Again, this required extensive communication among group members, who should go over previous data (time series and newspaper front pages) and reach an agreement about the perceived impact of special events. This promoted the foresight concepts of communication of opinions and consensus. Finally, the sixth week introduced Triggs monitoring method to identify systemic forecasting error and students had to adjust their forecasts towards more unbiased estimates. Students also had a chance to see how they ranked with regards to average forecasting accuracy among their fellow colleagues. The simulation concluded with the students answering the questionnaire once more (late responses). Educational aims and newly introduced concepts of every week are briefly summarized in Table 1.

After the conclusion of the simulation game, every student had to submit an individual report, accounting for critical choices made at various stages of the simulation and commenting on their efficiency. The intention for this report was to make students critically reflect on their choices and also make them aware that users display specific kinds of behavior in the process of using a Forecasting Support System (Goodwin et al., 2007).

\section{F $^{2}$ SS: a web-based Forecasting \& Foresight Support System}

The simulation exercise described in the previous section could have been carried out using traditional teaching and collaborative learning approaches, such as pen-and-paper solutions to the quantitative tasks and group meetings. The computational complexity of the former, though, demands the use of computers and specialized software, as it significantly speeds up the procedure and allows for more exploration on behalf of the students. Commercially available statistical and 
Table 1: Educational aims and introduced concepts for each week.

\begin{tabular}{|c|c|c|c|}
\hline Week & Educational Aim & Newly Introduced Concept(s) & Questionnaire \\
\hline 1 & $\begin{array}{l}\text { Getting familiar } \\
\text { with the simulation } \\
\text { layout }\end{array}$ & $\begin{array}{l}\text { - Select a suitable forecasting method via minimization } \\
\text { of a forecasting error measure. } \\
\text { - Use intuition to make judgmental adjustments. }\end{array}$ & No \\
\hline 2 & Utilizing soft info & $\begin{array}{l}\text { - Use soft info (newspaper cover) to make judgmental } \\
\text { adjustments. } \\
\text { - Meet the team and discuss choices. }\end{array}$ & No \\
\hline 3 & $\begin{array}{l}\text { Top-Down \& } \\
\text { Bottom-up } \\
\text { methodology }\end{array}$ & - Do a round of Bottom-up/Top-Down. & Yes \\
\hline 4 & $\begin{array}{l}\text { Qualitative } \\
\text { characteristics to } \\
\text { pick statistical } \\
\text { method }\end{array}$ & $\begin{array}{l}\text { - Select exponential smoothing method depending on } \\
\text { qualitative characteristics of time series. }\end{array}$ & No \\
\hline 5 & $\begin{array}{l}\text { Tackling special } \\
\text { events }\end{array}$ & $\begin{array}{l}\text { - Use seasonally-adjusted series to remove impact of pre- } \\
\text { vious special events. }\end{array}$ & No \\
\hline 6 & $\begin{array}{l}\text { Errors and forecast } \\
\text { monitoring }\end{array}$ & $\begin{array}{l}\text { - Use Triggs monitoring method to identify systematic } \\
\text { errors (bias). }\end{array}$ & Yes \\
\hline
\end{tabular}

business forecasting packages may look as an enticing solution at first glance; however, it is possible that the many customizable options might overwhelm the unfamiliar user and at the same time they do not address the complex communication needs that are a core element of any foresight support system. For such reasons, we opted for a custom built web-based $\mathrm{F}^{2} \mathrm{SS}$ as a platform for the simulation.

The specification for the web application can be drawn by the requirements of the simulation (Section 3) and the underlying rolling forecasting process (Figure 2). System features are listed in Table 2. A structured, three-tier architecture was used (Nikolopoulos et al., 2012). To begin with, a database scheme served as the data tier, where time series (year-period-value triplets) and their information (e.g. name, description) were stored. Student details and login information, as well the assignment of multiple time series per student was also supported. A distinct part of the database was reserved for users forecasts. Each forecast comprised of the year-period-value triplet, the statistical forecast and the method that was used for its preparation, the judgmental forecast and the weights used to produce the final forecast.

A set of modules served as the logic tier. A data module was used to extract data from the data base and build them into meaningful objects with functional interactions. All types of series were processed as time series objects, while forecasts and statistical/error metrics are processed as forecast and statistics objects, respectively. A statistic module accounts for the majority of statistical analysis and computations needed. A particular class (denoted by "Actions" in the diagram) enabled the interaction between the system administrator and the system itself. New or updated data would then be written back to the database via operations of the data module. A compact graphical description of the applications architecture is found in Figure 3.

The topmost tier, the presentation tier, was a graphical user interface (Figure 4) that exposed the systems various functions to the students. It comprised of a data visualization module, on 
Table 2: Features list of the proposed system.

\begin{tabular}{|c|c|}
\hline System Component & Features \\
\hline Data & $\begin{array}{l}\text { - Time series info. } \\
\text { - Download spreadsheet. } \\
\text { - Navigate through different series. } \\
\text { - Plot chart of series (original, deseasonalized, forecast model, final forecasts). }\end{array}$ \\
\hline View & - Chart display customization. \\
\hline Statistical Analysis & $\begin{array}{l}\text { - Descriptive statistics (minima, maxima, mean, standard deviation, coefficient of } \\
\text { variation). } \\
\text { - Forecast accuracy/bias. } \\
\text { - Seasonal indices (decomposition). }\end{array}$ \\
\hline Forecast & $\begin{array}{l}\text { - Statistical forecasting. } \\
\text { - Optimized parameters. } \\
\text { - Judgmental adjustments. }\end{array}$ \\
\hline Submit & - History of submissions \\
\hline Monitoring & $\begin{array}{l}\text { - Triggs series monitoring method. } \\
\text { - Comparison among users. }\end{array}$ \\
\hline Communication & $\begin{array}{l}\text { - Chat service. } \\
\text { - Bottom-up/Top-down (cross-sectional aggregation/disaggregation). }\end{array}$ \\
\hline $\begin{array}{l}\text { Control Panel } \\
\text { (Administrator) }\end{array}$ & $\begin{array}{l}\text { - Manage user accounts. } \\
\text { - Manage series. } \\
\text { - Push data to users. }\end{array}$ \\
\hline
\end{tabular}

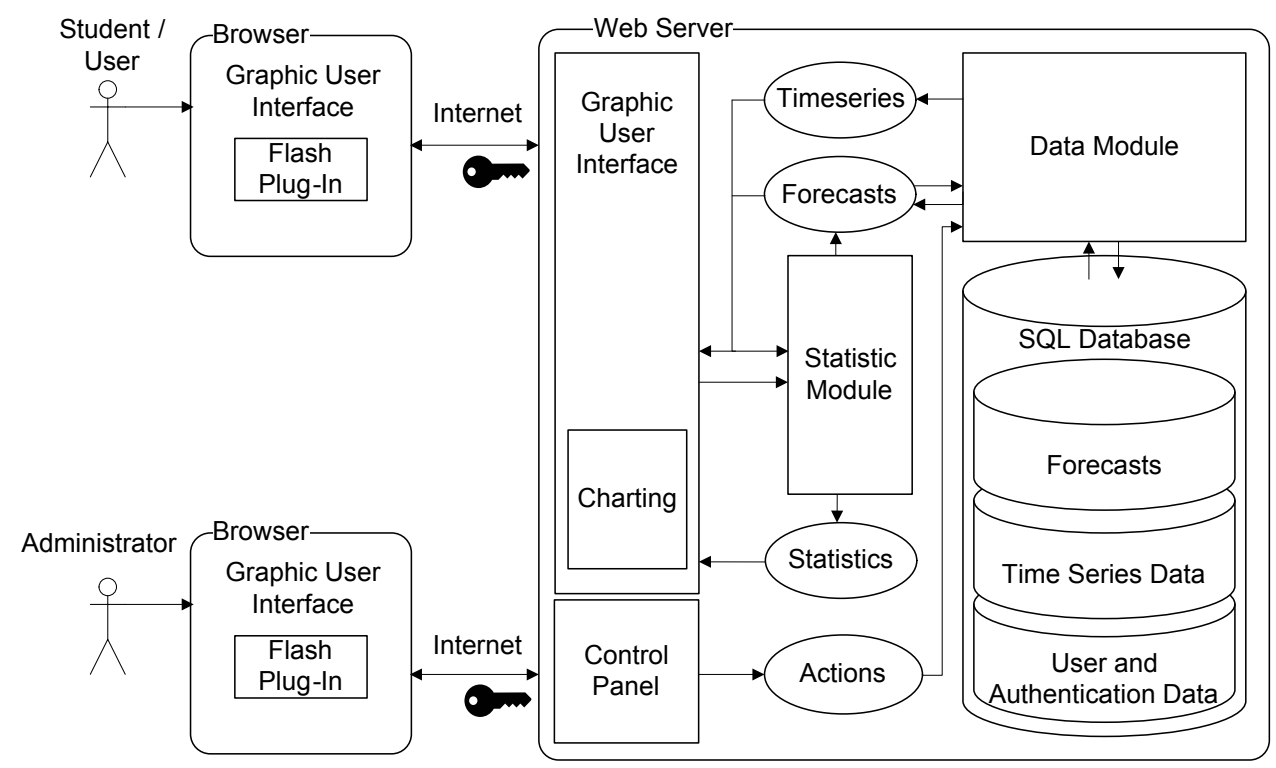

Figure 3: Web system's architecture. 
which time series and forecasts could be plotted against a timeline. A ribbon on the top of the page with various tabs (Figure 5) represented the interactive part of the learning environment. This control panel provided the following features:

- Data tab: one could view general information about the time series (series name and description, number of observations, periods per year and seasonality), switch the time series they are working on, as well as download a spreadsheet of the data.

- View tab: provided the means of customizing the display properties of the chart. The different series (original, seasonally adjusted, model fit, and forecast) could be displayed individually or together at the same chart.

- Analysis tab: presented a statistical analysis of the time series, showing the values of statistical characteristics, whether typical of the series itself or depending also on the model fit in question (accuracy metrics). A separate section was reserved for the presentation of seasonal indices, via simple quotation of their values or through a seasonality chart. The multiplicative seasonality model was used to decompose the series. Deseasonalization and reseasonalization processes were automatically carried out.

- Forecast tab: provided the core tools of implementation of the forecasting process. Students could choose among several forecast methods to generate a statistical forecast, define the value of the judgmental forecast and specify the way the final forecast would be derived. Methods parameters were automatically optimized based on minimization of in-sample errors. The final result was then drawn on the chart, in order to provide feedback to the user.

- Submit tab: Final forecasts could be submitted and all available previous submissions were listed in detail.

- Students could examine the accuracy of their forecasts via the Monitoring tab. Specifically, they could view various error metrics of their forecasts, with original data as a benchmark, or read an error bar chart built using Triggs series monitoring method. This chart depicted the randomness of errors and helped users take corrective actions to produce more unbiased predictions.

In addition to the above forecasting features, the system included a communications platform to allow for foresight routines. In particular, users within the same group (company) could communicate with one another through a built-in chatting service. This allowed for (a)synchronous discussions about their choices and let information flow through the hierarchical levels. Students used this platform to communicate their opinions and interpretation of information about the future either by posting their views or engaging in real-time discussions. To further enhance information flow and instigate collaboration, a bottom-up/top-down feature was also implemented. It displayed a chart of the hierarchical structure of the company, each users position within it and their forecasts. It also automatically aggregated bottom level forecasts to produce bottom-up forecasts and split the leaders estimates to produce top-down forecasts for their subordinates. By comparing their own estimates with the suggested estimates coming from the other hierarchical level users could compare their degree of agreement (consensus) and either justify their reason for divergence or take actions towards reconciliation. The foresight capabilities of the proposed system are presented in Figure 6.

A similar environment was also available to the administrators, with the addition of a control panel, which offered account and series management and exercise supervision tools. It was also used to push new data to the users, thus "rolling" into the next prediction round. 


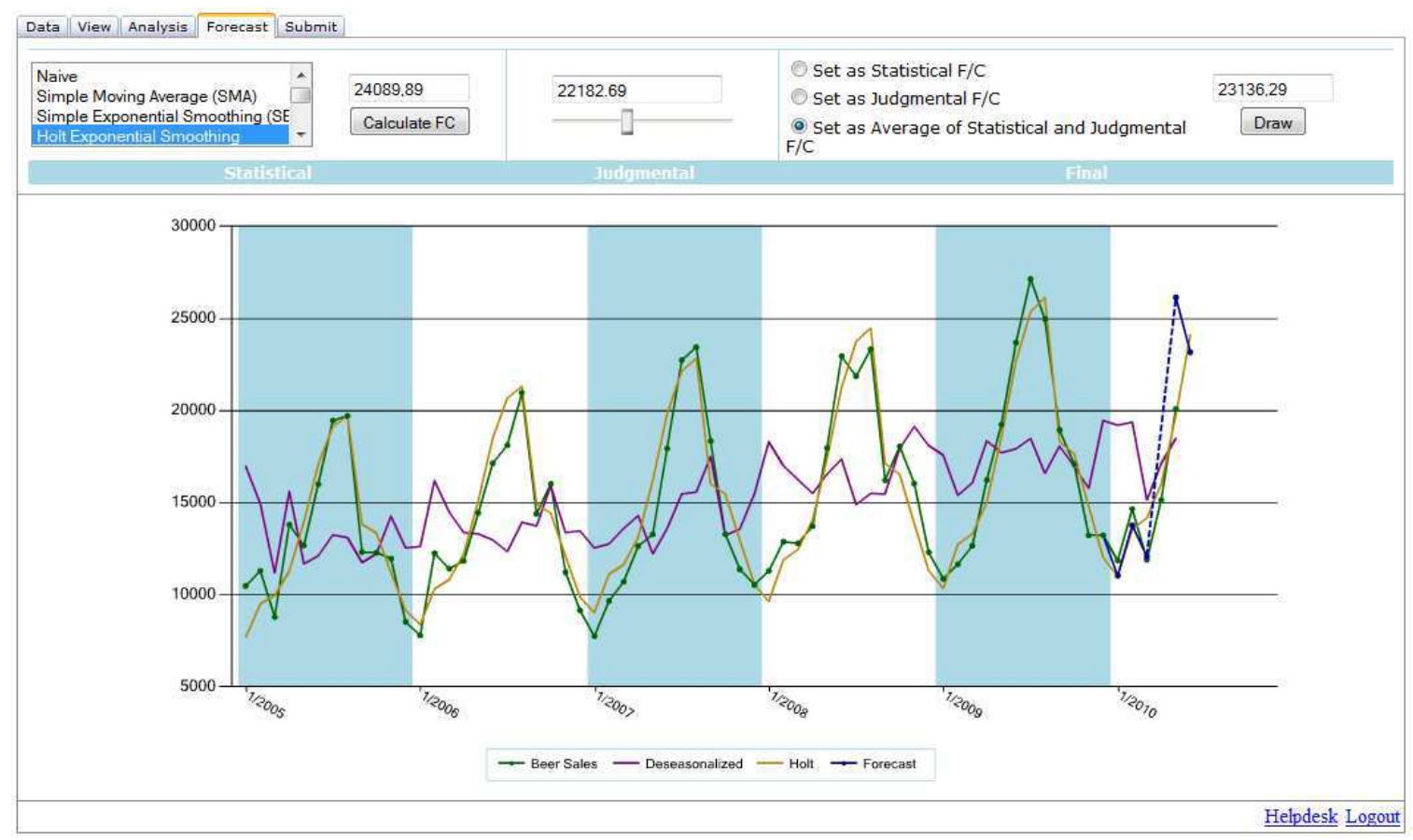

Figure 4: Screenshot of the system's main page.

Although most actions of the simulation were integrated into our system, some external tools were also used. For example, each weeks tasks and guidelines were emailed to the students along with the newspaper covers. To facilitate ease of access and use, help desk support was provided to the students all along the duration of the exercise, through which they could have both technical and educational questions pertaining to the system or the exercise, respectively, timely answered via email. Moreover, students could download data in spreadsheet form and use any external spreadsheet application to manipulate and further analyze the data.

The web application was programmed on its entirety in Visual Basic, using the ASP .NET framework and a Microsoft SQL Server database. The application was accessible online through any custom Internet browser with installed Flash Plug-In. Charts and plots were drawn using the Dundas Chart for .NET component.

\section{Data analysis}

\subsection{Setup and data collection}

All students, including the ones not participating in the exercise, had to sit the courses final exam. The exam papers were marked so that each student was given an exam score. Exam scores range from 0 to 10 (full grade) and have one decimal point precision.

The fact that any student enrolled to the course could decide of their own accord to participate or not in the exercise, an ethical limitation to the experimental setup to guarantee nondiscrimination among students, creates a self-selection effect that makes determination of causality in statistical comparisons between the two groups (participating and non-participating) problematic. 


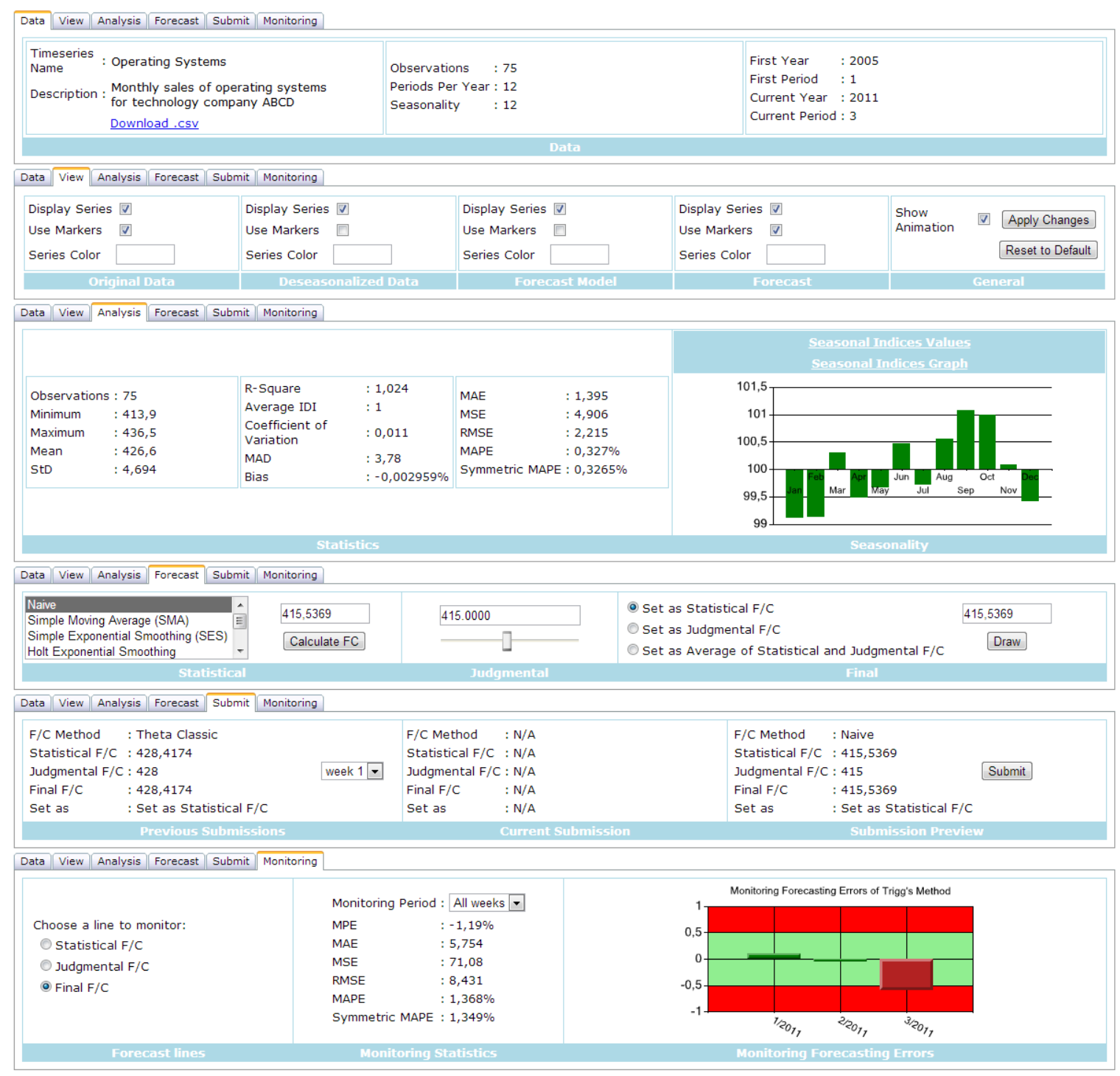

Figure 5: Screenshot of the system's ribbon menu. 

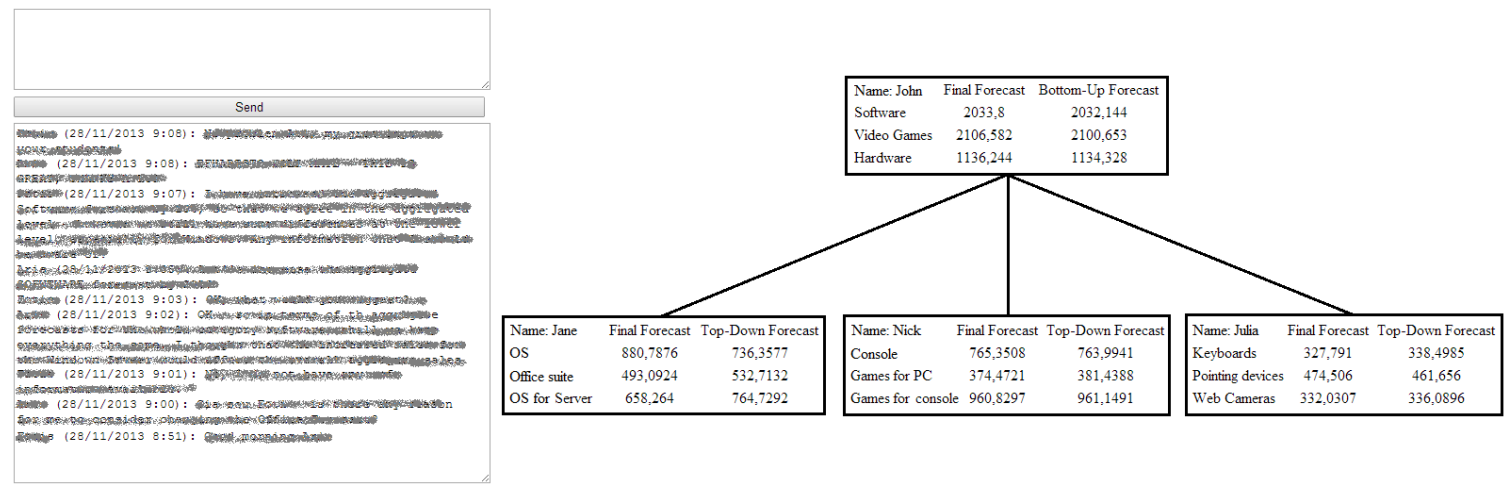

Figure 6: The system provides capabilities for discussions between the decision makers at the various levels of the hierarchy, as well as a graphical illustration of the companys structure.

Questionnaire techniques were used to get feedback on several concepts. In Table 3 we present the questionnaire used, along with the respective concept each item is meant to assess (this information was not made available to the students during assessment). Participating students were instructed to give answers in the integer score scale from one to five (1: Not at all, ..., 5: Completely). In particular, this questionnaire would provide the necessary feedback for measuring student satisfaction from team cooperation (Q1), degree of influence from team cooperation (Q2), system sufficiency (Q3), perceived learning effect (Q4) and recommendability of the exercise (Q5). Answers to the questionnaire were collected twice, at an early (end of third week) and at a later (end of sixth week) stage of the simulation.

Table 3: Questionnaire Layout.

\begin{tabular}{clc}
\hline$\#$ & \multicolumn{1}{c}{ Question } & Assessed Concept \\
\hline Q1 & $\begin{array}{l}\text { How satisfied were you from the cooperation with } \\
\text { other team members? }\end{array}$ & $\begin{array}{c}\text { Satisfaction from } \\
\text { team cooperation }\end{array}$ \\
Q2 & $\begin{array}{l}\text { How much was your final decision influenced by } \\
\text { other hierarchical levels? }\end{array}$ & $\begin{array}{c}\text { Influence from team } \\
\text { co-operation }\end{array}$ \\
Q3 & $\begin{array}{l}\text { How much sufficient/efficient was the online sys- } \\
\text { tem for the objectives so far? }\end{array}$ & System sufficiency \\
Q4 & $\begin{array}{l}\text { How much do you believe this exercise has helped } \\
\text { you understand standard forecasting practices? }\end{array}$ & $\begin{array}{c}\text { Perceived learning } \\
\text { effect }\end{array}$ \\
Q5 & $\begin{array}{l}\text { To what extent would you recommend this exer- } \\
\text { cise to other students of forecasting courses? }\end{array}$ & $\begin{array}{c}\text { Recommendability } \\
\text { of exercise }\end{array}$ \\
\hline
\end{tabular}

\subsection{Statistical analysis and discussion}

Descriptive statistics for the exam scores of the two groups are presented in Table 4. Nine students deferred their examination for that period and thus no exam score is available for them. The median score for the group that participated in the exercise (74 students) was 5.55 , whereas for the group of non-participating students (15 students) it was 2.50. A Mann-Whitney test shows that the difference of the medians is statistically significant at $=0.001$ level of significance. Nevertheless, 
self-assignment of the students in the two groups does not allow us to attribute this difference to participation in the exercise; thus, this result should be taken with a grain of salt.

Table 4: Descriptive statistics for exam score.

\begin{tabular}{ccc}
\hline Statistic & $\begin{array}{c}\text { Students participating in } \\
\text { the exercise }\end{array}$ & $\begin{array}{c}\text { Students non-participating } \\
\text { in the exercise }\end{array}$ \\
\hline$n$ Valid & 74 & 15 \\
$n$ Missing & 9 & 0 \\
Minimum & 0.5 & 0.3 \\
Maximum & 8.7 & 7.1 \\
Mean & 5.32 & 3.23 \\
Median & 5.55 & 2.50 \\
St. Dev. & 1.97 & 2.24 \\
\hline
\end{tabular}

We bypass this limitation by focusing on the group of participating students and comparing their early and late responses to the questionnaire. Under this setup, any change in the assessed quantities can be attributed to the effect of the exercise on the students.

The frequency distribution and descriptive statistics for the answer scores per question are presented in Tables 5 and 6 , respectively. It is apparent that feedback is largely positive. In particular, students seem to believe that the exercise had a positive educational effect and most of them would definitely recommend taking part in such an exercise to other students of Business Forecasting.

The discrete, ordinal nature of the responses makes non-parametric rank tests, such as the ones used below, a more suitable alternative to parametric ones that make the normality assumption (Conover, 1999). Consistently, the Spearmans rho correlation coefficients will be used to explore correlations among responses to different questions.

In either of the questionnaire rounds, no statistically significant difference in measures of central tendency (medians, as shown by Mann-Whitney test at the $=0.05$ level of significance) was found in the respective responses between the groups of students in the upper and lower levels of the company hierarchy. This is in agreement with our intuition, since all students had to carry out the same tasks, regardless of their position in the company, and allows us to treat the responses of the two groups jointly. It also showcases that random allocation to one of the two groups is fair to the students, as perceived learning effect and satisfaction seem to be invariant to it.

Furthermore, Wilcoxon signed-rank tests show that between early and late responses there was a significant increase in the median responses at the $\alpha=0.05$ level of significance for the received satisfaction from co-operation ( $\mathrm{Q} 1, \mathrm{p}$-value $<0.001)$, degree of influence from other hierarchical levels $(\mathrm{Q} 2$, p-value $<0.001)$ and perceived learning effect $(\mathrm{Q} 4, \mathrm{p}$-value $=0.021)$. We attribute this increase in the Q1 and Q2 scores to the strengthening of the on-going collaboration between the members of a company over the weeks, which was achieved through encouragement of student communication. Specific tasks included (a)synchronous discussions to translate the soft information given in the weekly newspaper and it was suggested that students try to achieve reconciliation of their forecasts through repeated rounds of bottom-up/top-down forecasting. As more forecasting and foresight features were being brought into the attention of students, creating a richer and more realistic simulated business experience, the reported perceived learning effect also displayed an increase. 
Table 5: Distribution of scores per question (Q1-Q5).

\begin{tabular}{|c|c|c|c|c|c|}
\hline \multirow{2}{*}{$\#$} & \multirow{2}{*}{ Response } & \multicolumn{2}{|c|}{ Early Responses } & \multicolumn{2}{|c|}{ Late Responses } \\
\hline & & Frequency & Percent & Frequency & Percent \\
\hline \multirow{5}{*}{ Q1 } & 1 & 13 & 15.7 & 5 & 6.0 \\
\hline & 2 & 24 & 28.9 & 11 & 13.3 \\
\hline & 3 & 31 & 37.3 & 36 & 43.4 \\
\hline & 4 & 11 & 13.3 & 26 & 31.3 \\
\hline & 5 & 4 & 4.8 & 5 & 6.0 \\
\hline \multirow{5}{*}{ Q2 } & 1 & 39 & 47.0 & 7 & 8.4 \\
\hline & 2 & 26 & 31.3 & 27 & 32.5 \\
\hline & 3 & 17 & 20.5 & 42 & 50.6 \\
\hline & 4 & 0 & 0.0 & 7 & 8.4 \\
\hline & 5 & 1 & 1.2 & 0 & 0.0 \\
\hline \multirow{5}{*}{ Q3 } & 1 & 0 & 0.0 & 0 & 0.0 \\
\hline & 2 & 3 & 3.6 & 4 & 4.8 \\
\hline & 3 & 21 & 25.3 & 21 & 25.3 \\
\hline & 4 & 41 & 49.4 & 42 & 50.6 \\
\hline & 5 & 18 & 21.7 & 16 & 19.3 \\
\hline \multirow{5}{*}{ Q4 } & 1 & 0 & 0.0 & 0 & 0.0 \\
\hline & 2 & 8 & 9.6 & 2 & 2.4 \\
\hline & 3 & 36 & 43.4 & 38 & 45.8 \\
\hline & 4 & 33 & 39.8 & 31 & 37.3 \\
\hline & 5 & 6 & 7.2 & 12 & 14.5 \\
\hline \multirow{5}{*}{ Q5 } & 1 & 1 & 1.2 & 0 & 0.0 \\
\hline & 2 & 0 & 0.0 & 1 & 1.2 \\
\hline & 3 & 3 & 3.6 & 4 & 4.8 \\
\hline & 4 & 36 & 43.4 & 34 & 41.0 \\
\hline & 5 & 43 & 51.8 & 44 & 53.0 \\
\hline
\end{tabular}


Table 6: Descriptive statistics for answer scores per question (Q1-Q5).

\begin{tabular}{|c|c|c|c|c|c|c|}
\hline & Statistic & Q1 & Q2 & Q3 & Q4 & Q5 \\
\hline \multirow{7}{*}{ 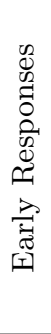 } & $n$ Valid & 83 & 83 & 83 & 83 & 83 \\
\hline & $n$ Missing & 0 & 0 & 0 & 0 & 0 \\
\hline & Minimum & 1 & 1 & 2 & 2 & 1 \\
\hline & Maximum & 5 & 5 & 5 & 5 & 5 \\
\hline & Mode & 3 & 1 & 4 & 3 & 5 \\
\hline & Mean & 2.63 & 1.77 & 3.89 & 3.45 & 4.45 \\
\hline & Median & 3 & 2 & 4 & 3 & 5 \\
\hline \multirow{7}{*}{ 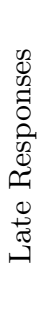 } & $n$ Valid & 83 & 83 & 83 & 83 & 83 \\
\hline & $n$ Missing & 0 & 0 & 0 & 0 & 0 \\
\hline & Minimum & 1 & 1 & 2 & 2 & 2 \\
\hline & Maximum & 5 & 4 & 5 & 5 & 5 \\
\hline & Mode & 3 & 3 & 4 & 3 & 5 \\
\hline & Mean & 3.18 & 2.59 & 3.84 & 3.64 & 4.46 \\
\hline & Median & 3 & 3 & 4 & 4 & 5 \\
\hline
\end{tabular}

The Spearmans rho correlation coefficients for the later responses are displayed in Table 7 . We observe that student satisfaction from cooperation (Q1) and degree of influence from other hierarchical levels (Q2) exhibits a weak correlation, whereas the perceived learning effect (Q4) is moderately correlated with system sufficiency (Q3) and students recommendation of the exercise to other students (Q5). Furthermore, Q3 and Q5 are also weakly correlated. These correlations intuitively split the questions into two groups: Q1-Q2 which relate to student communication and information flow between hierarchical and Q3-Q5 which stand for learning effect and student satisfaction from the system overall.

Table 7: Spearman's rho correlation coefficients (Q1-Q5, late responses).

\begin{tabular}{cccccc}
\hline \multicolumn{7}{c}{ Q1 } & Q2 & Q3 & Q4 & Q5 \\
\hline Q1 & 1 & & & & \\
Q2 & $0.269^{\mathrm{a}}$ & 1 & & & \\
Q3 & 0.168 & 0.045 & 1 & & \\
Q4 & 0.079 & 0.067 & $0.385^{\mathrm{b}}$ & 1 & 1 \\
Q5 & 0.199 & 0.053 & $0.289^{\mathrm{b}}$ & $0.437^{\mathrm{b}}$ & 1 \\
\hline${ }^{\mathrm{a}}$ Correlation is significant at the 0.05 level (2-tailed). \\
Correlation is significant at the 0.01 level (2-tailed). \\
\hline
\end{tabular}

\subsection{Limitations}

Abstract quantities, such as actual learning impact and student satisfaction, have subtle and elusive definitions, let alone ways to measure them; therefore, we had to resort to reported perceived estimates. Such responses are subject to bias, as the linguistic terms (e.g. not at all, somewhat, completely) may be perceived differently among students. Moreover, in order to keep the questionnaires short, there was only one question per variable of interest. A more extensive 
questionnaire with multiple questions per factor would have allowed for more elaborate analysis, such as factor analysis and parametric methods on the identified factors.

Even more complicated or objective measures of educational outcome, such as the score of an end term exam, may not be sufficient. Different means of assessment might capture different nuances of the quantity of interest, so that their numerical values might be uncorrelated or even divergent. In particular, the exam score quantifies the students analytical problem solving abilities, numerical precision, understanding of theory etc, whereas a questionnaire item like Q4 emphasizes the students self-satisfaction with internalization of covered material, self-confidence that they would do well in a real Business Forecasting scenario etc. Indeed, we find that there is no significant correlation between the exams score and the answer score (late responses) for Q4 (Spearmans rho correlation coefficient is 0.003$)$.

As discussed earlier, the ethical limitation to guarantee non-discrimination among students created a self-selection effect that makes determination of causality problematic. An additional statistical consideration is the small size of the group sizes.

The educational setting of the simulation that called for specific forecasting guidelines and hints to highlight to the students particular aspects of forecasting and foresight leads to some further limitations. The use of different time series among users, guided selection of statistical forecasting method and the effect of special events (soft info) makes further analysis of behavioral (e.g. which statistical methods do users favor, what kind of judgmental adjustments do they make) and performance (e.g. forecasting errors) aspects challenging. It would be interesting to explore how novice forecasters would act and perform in a fully unguided scenario and compare that to other types of forecasters (e.g. experts).

\section{Conclusions}

The current papers proposes a Forecasting \& Foresight Support System $\left(\mathrm{F}^{2} \mathrm{SS}\right)$, which combines standard features from a business forecasting system with aspects of communication, so that soft data and external information can be analyzed in a collective manner. The development of the prototype system was completed on a web-based design, to make the system remotely accessible, allowing for active networking and collaboration.

The application of the proposed system in the context of an elective business simulation exercise had a positive impact on students enrolled in a Business Forecasting course, in terms of perceived learning impact and satisfaction. Those who participated could experiment with various processes of forecasting and foresight, thus building up intuition and realism in their expectancies. Results indicate a satisfactory level of cooperation between students in the same team, while influence from other hierarchical levels increases significantly as new features become available, new questions are arising and the simulation becomes more realistic overall. The questionnaire results were very positive, complimenting on the impact and impression the web system had on the students. Therefore, such an exercise was not only true to its educational aim, but it also fitted well with the expectations and needs of students. The wide variety of tools supported by such a system makes it highly customizable to the needs of other Business Forecasting training programs.

We believe that the findings of this study can be safely generalized in the case of professional forecasters (forecasting managers, demand planners, etc.). Standard executive training courses can be expanded with the addition of the business forecasting simulation exercise described in the current paper. This would enable the trainees not only to directly and automatically apply the statistical methods being taught, but also they will be in position to adjust the statistical outputs 
on the light of soft information or as a result of collaborative effort amongst the members of a company. Through simulated exercises and real-business scenarios, demand planners will be able to avoid bad practices in forecasting and, thus, increase their performance.

The above findings are also very important from a managerial and decision-making perspective. There is evidence that a system that combines features of both forecasting and foresight processes can enhance user experience, while allowing for a deeper understanding of the underlying process. Most importantly, by enabling collaboration and communication between members of the same team, an increased impact from members of different hierarchical levels is observed, coupled with increased satisfaction in terms of collaboration. We suggest that the application of this system design in real life will lead to increased operational performance, making forecasts highly acceptable across managers of different hierarchical levels.

Regarding possible extensions, the integration of more qualitative structured or semi-structured methods seems necessary. The Delphi method (Rowe and Wright, 1999, 2001) and Structured Analogies (Green and Armstrong, 2007) would serve this purpose and would act as supplementary to the existing interaction groups approach. In terms of educational experience, learning alternatives should be considered and compared in terms of efficiency with the proposed $\mathrm{F}^{2} \mathrm{SS}$. Finally, it is worth examining why a large proportion of students chose not to participate in such an elective educational exercises, despite the final positive feedback and high recommendation rates from their colleagues.

\section{Acknowledgements}

We would like thank all students of the course Forecasting Techniques at the Electrical and Computer Engineering School of National Technological University of Athens who took part in this study.

\section{References}

Armstrong, J. S., Collopy, F., 1998. Integration of statistical methods and judgment for time series forecasting: principles from empirical research. In: Wright, G., Goodwin, P. (Eds.), Forecasting with judgment. John Wiley and Sons, Chichester, pp. 269-293.

Armstrong, J. S., Yokum, J. T., 2001. Potential diffusion of expert systems in forecasting. Technological Forecasting and Social Change 67, 93-103.

Assimakopoulos, V., Nikolopoulos, K., 2000. The Theta model: a decomposition approach to forecasting. International Journal of Forecasting 16, 521-530.

Athanasopoulos, G., Ahmed, R. A., Hyndman, R. J., 2009. Hierarchical forecasts for australian domestic tourism. International Journal of Forecasting 25, 146-166.

Banuls, V. A., Salmeron, J. L., 2011. Scope and design issues in foresight support systems. International Journal of Foresight and Innovation Policy 7, 338-351.

Brown, R. G., 1956. Exponential Smoothing for Predicting Demand. Arthur D. Little Inc, Cambridge, Massachusetts.

Conover, W. J., 1999. Practical Nonparametric Statistics (3rd ed.). John Wiley and Sons, New York.

Cuhls, K., 2003. From forecasting to foresight processes - new participative foresight activities in germany. Journal of Forecasting 22, 93-111.

Dangerfield, B. J., Morris, J. S., 1992. Top-down or bottom-up: Aggregate versus disaggregate extrapolations. International Journal of Forecasting 8, 233-241.

Fildes, R., Goodwin, P., 2007. Good and bad judgment in forecasting: lessons from four companies. Foresight 8 , 5-10.

Fildes, R., Goodwin, P., 2013. Forecasting support systems: What we know, what we need to know. International Journal of Forecasting 29, 290-294. 
Fildes, R., Goodwin, P., Lawrence, M., Nikolopoulos, K., 2009. Effective forecasting and judgmental adjustments: an empirical evaluation and strategies for improvement in supply-chain planning. International Journal of Forecasting $25,3-23$.

Fortune, J., 2007. The virtual learning environment: An alternative, flexible and accessible method of neonatal nurse education. Journal of Neonatal Nursing 13, 231-235.

Gardner, E. S., McKenzie, E., 1985. Forecasting trends in time series. Management Science 31, 1237-1246.

Goodwin, P., Fildes, R., Lawrence, M., Nikolopoulos, K., 2007. The process of using a forecasting support system. International Journal of Forecasting 23, 391-404.

Green, K. C., Armstrong, J. S., 2007. Structured analogies for forecasting. International Journal of Forecasting 23, 365-376.

Gross, C. W., Sohl, J. E., 1990. Dissagregation methods to expedite product line forecasting. Journal of Forecasting 9, 233-254

Haak, D. C., HilleRisLambers, J., Pitre, E., Freeman, S., 2011. Increased structure and active learning reduce the achievement gap in introductory biology. Science 332, 1213-1216.

Helic, D., H, M., Scherbakov, N., 2000. Web based training: What do we expect from the system. Proceedings of ICCE 2000, Taiwan, 1689-1694.

Holt, C. C., 1957. Forecasting seasonal and trends by exponentially weighted moving averages. Office of Naval Research 52

Hunter, B., 1989. Designing educational software for the information age: Dilemmas and paradoxes. Education and Computing 5, 111-117.

Hyndman, R. J., Ahmed, R. A., Athanasopoulos, G., Shang, H. L., 2011. Optimal combination forecasts for hierarchical time series. Computational Statistics and Data Analysis 55, 2579-2589.

Hyndman, R. J., Athanasopoulos, G., 2013. Forecasting: principles and practice. OTexts (http://otexts.com/fpp/), Melbourne, Australia.

Hyndman, R. J., Khandakar, V., 2008. Automatic time series forecasting: The forecast package for R. Journal of Statistical Software 27, 1-22.

Kulik, J. A., 1994. Meta-analytic studies of findings on computer-based instruction. In: Baker, E. L., O’Neil, H. F. (Eds.), Technology assessment in education and training. Lawrence Erlbaum, pp. 9-33.

Makridakis, S., Andersen, A., Carbone, R., Fildes, R., Hibon, M., Lewandowski, R., Newton, J., Parzen, E., Winkler, R., 1982. The accuracy of extrapolation (time series) methods: Results of a forecasting competition. Journal of Forecasting 1, 111-153.

Makridakis, S., Assimakopoulos, V., Bougioukos, N., Nikolopoulos, K., Petropoulos, F., Pagourtzi, E., 2008. Pythia: an intelligent forecasting support system. Proceedings of the 28th International Symposium on Forecasting, nice, france.

Makridakis, S., Hibon, M., 2000. The M3-Competition: results, conclusions and implications. International Journal of Forecasting 16, 451-476.

Makridakis, S., Wheelwright, S. C., Hyndman, R. J., 1998. Forecasting: Methods and Applications (3rd ed.). John Wiley and Sons, New York.

Martin, B. R., Johnston, R., 1999. Technology foresight for wiring up the national innovation system: Experiences in Britain, Australia, and New Zealand. Technological Forecasting and Social Change 60, 37-54.

McKone, K., Bozewicz, J., 2003. The ism simulation: Teaching integrated management concepts. Journal of Management Education 27, 497-515.

Nikolopoulos, K., Litsa, A., Petropoulos, F., Bougioukos, V., Khammash, M., in press. Relative performance of methods for forecasting unique events. Journal of Business Research, forthcoming.

Nikolopoulos, K., Litsa, A., Petropoulos, F., Metaxiotis, K., Assimakopoulos, V., 2012. A web forecasting system supporting policy implementation: the case of 'digital planning' in Greece. International Journal of Business Information Systems 11, 397-409.

Ord, K., Fildes, R., 2013. Principles of Business Forecasting. South-Western Cengage Learning, Mason, Ohio.

Parikh, M., Verma, S., 2002. Utilizing internet technologies to support learning: an empirical analysis. International Journal of Information Management 22, 27-46.

Ready, K. J., Hostager, T. J., Lester, S., Bergmann, M., 2004. Beyond the silo approach: Using group support systems in organizational behavior classes to facilitate student understanding of individual and group behavior in electronic meetings. Journal of Management Education 28, 770-789.

Rowe, G., Wright, G., 1999. The Delphi technique as a forecasting tool: issues and analysis. International Journal of Forecasting 15, 353-375.

Rowe, G., Wright, G., 2001. Expert opinions in forecasting. role of the Delphi technique. In: Armstrong, J. S. 
(Ed.), Principles of Forecasting: A Handbook for Researchers and Practitioners. Kluwer Academic Publishers, pp. 125-144.

Sawyer, J. E., Ferry, D. L., Kydd, C., 2001. Learning about and from group support systems. Journal of Management Education 25, 352-371.

Shannon, P. W., Krumwiede, K. R., Street, J. N., 2010. Using simulation to explore lean manufacturing implementation strategies. Journal of Management Education 34, 280-302.

Sivin-Kachala, J., Bialo, E. R., 2000. 2000 Research report on the effectiveness of technology in schools (7th ed.). Software \& Information Industry Association, Washington, DC.

Skulimowski, A. M. J., 2012. A foresight support system to manage knowledge on information society evolution. Lecture Notes in Computer Science 7710, 246-259.

Song, H., Gao, B. Z., Lin, V. S., 2013. Combining statistical and judgmental forecasts via a web-based tourism demand forecasting system. International Journal of Forecasting 29, 295-310.

Stricker, D., Weibel, D., Wissmath, B., 2011. Efficient learning using a virtual learning environment in a university class. Computers \& Education 56, 495-504.

Tavanidou, E., Nikolopoulos, K., Metaxiotis, K., Assimakopoulos, V., 2003. eTIFIS: An innovative e-forecasting web application. International Journal of Software Engineering and Knowledge Engineering 13, 215-236.

Trigg, D. W., 1964. Monitoring a forecasting system. Operational Research Quarterly 15, 271-274.

Van der Meulen, B., De Wilt, J., Rutten, H., 2003. Developing a future for agriculture in the Netherlands: a systematic exploration of the strategic value of foresight. Journal of Forecasting 22, 219-233. 